\title{
Coğrafi Bilgi Sistemleri (CBS) Ortamında Analitik Hiyerarşi Prosesiyle (AHP) Organik Gübre Üretim Tesisi Uygunluk Analizi: Tekirdağ İli Örneği
}

Compliance Analysis of Organic Fertilizer Production Plant with Analytical Hierarchy Process (AHP) in Geographical Information Systems (GIS) Environment: The Case of Tekirdağ Province

\section{Burak GÜRKAN ${ }^{1}$, Bengisu ÖDEKER ${ }^{2}$, Hikmet KATIRCIOĞLU ${ }^{3 *}$}

\section{$\ddot{\mathbf{O z}}$}

Organik gübre üretim tesislerinin yer seçimi, tarımsal işletmeler ve tarım sektörü açısından kritik öneme sahip bir konudur. Tesis yerinin uygunluk analizi sonucuna göre seçilmesinin tarım sektörüne ve çevreye nasıl bir katkı sağlayacağı üzerinde durulan bu çalışmada, Tekirdağ ili çalışma alanı olarak seçilmiştir. Bu doğrultuda Analitik Hiyerarşi Sürecinde temel ve alt kriterler belirlenmiş, alt kriter grupları içerisindeki organik gübre tesisi sayısı adet olarak belirtilmiştir. Ortaya çıkan kriterler önem derecelerine göre yeniden sınıflandırılmıştır. Temel kriterler: fiziki, çevresel ve sosyo-ekonomik kriterler; alt kriterler ise eğim, yükseklik, büyük toprak grupları, arazi kullanımı, arazi kullanım kabiliyeti sınıfları, kara-demir yollarına, limanlara, yerleşim merkezlerine ve elektrik enerjisi iletim hatlarına olan mesafe olarak belirlenmiştir. Her bir kriter için tutarlılık oranları hesaplanmıştır. Analitik Hiyerarşi Sürecinde hesaplanan kriter ağırlıkları Coğrafi Bilgi Sistemleri ortamına ArcGIS 10.5 yazılımına aktarılarak ve organik gübre tesisi için uygunluk haritası elde edilmiştir. Elde edilen bulgular doğrultusunda Tekirdağ ilinin \%81.01'i çok yüksek-yüksek-orta uygunluk göstermekte ve mevcut organik gübre tesisleri bu alanlarda bulunmaktadır. İlin \%8.20'si çok düşük uygunlukta bulunmuştur. Bunun sebebi de bu bölgelerin milli park ve ormanları barındırmasından kaynaklanmaktadır. Bir organik gübre tesisinin tarım alanı yakınında olması ham maddeye yakınlık açısından uygun olup ülkeye ekonomik girdi kapsamında da sürdürülebilirliği ifade etmektedir. $\mathrm{Bu}$ çalışmada ulusal/uluslararası tarım işletmeleri uygun alan seçimi karar mekanizmasında kullanılmak üzere CBS ortamındaki AHP yöntemi, Tekirdağ ili örneği üzerinden önerilmektedir. Günümüzde uygun alan seçimi karar mekanizmalarında genellikle çevre etki değerlendirme raporları dikkate alınmaktadır. Ancak bu raporlarda veya karar mercilerinde AHP ve benzeri matematiksel modellemeler kullanılmamaktadır. Bu çalışmada örnek bölge seçilen Tekirdağ iline (\%75.11'i tarım alanı, toprağ $\% 90$ yetersiz organik madde) ait modellemeden elde edilen verilere göre organik gübre ihtiyacını karşılayacak tesis sayısının güneybatı bölgesinde de kurularak sayısının arttırılması önerilmektedir.

Anahtar Kelimeler: Coğrafi Bilgi Sistemleri, Analitik Hiyerarşi Süreci, Tekirdağ, Organik Gübre Tesisi, Uygunluk Analizleri

\footnotetext{
1Burak GÜRKAN, Gazi Üniversitesi Eğitim Fakültesi Biyoloji Eğitimi A.B.D., Ankara, Türkiye. E-mail: burak.gurkan@gazi.edu.tr (D) OrcID: 0000-0001-92529515 .

${ }^{2}$ Bengisu ÖDEKER, Ankara Üniversitesi Dil ve Tarih Coğrafya Fakültesi Fiziki Coğrafya A.B.D., Ankara, Türkiye. E-mail: bodeker@ankara.edu.tr $[$ iD OrcID: 0000-0002-2787-2250.

3*Sorumlu Yazar/Corresponding Author: Hikmet KATIRCIOĞLU, Gazi Üniversitesi Eğitim Fakültesi Biyoloji Eğitimi A.B.D., Ankara, Türkiye. E-mail: hturk@gazi.edu.tr (D) OrcID: 0000-0002-4866-6106.

Atıf/Citation: GÜRKAN, B., ÖDEKER B., KATIRCIOĞLU H. Coğrafi Bilgi Sistemleri (CBS) Ortamında Analitik Hiyerarşi Prosesiyle (AHP) Organik Gübre Üretim Tesisi Uygunluk Analizi: Tekirdağ İli Örneği. Tekirdağ Ziraat Fakültesi Dergisi, 18 (4), 718-729.

(CBu çalışma Tekirdağ Namık Kemal Üniversitesi tarafından Creative Commons Lisansı (https://creativecommons.org/licenses/by-nc/4.0/) kapsamında yayınlanmıştır. Tekirdağ 2021
} 


\begin{abstract}
Choosing the location of organic fertilizer production facilities is a critical issue for agricultural enterprises and the agricultural sector. In this study, which is focused on how the selection of the facility location according to the results of the suitability analysis will contribute to the agricultural sector and the environment, Tekirdağ province was chosen as the study area. In this direction, basic and sub-criteria were determined in the Analytical Hierarchy Process, and the number of organic fertilizer plants in the sub-criteria groups was specified. The resulting criteria were reclassified according to their importance. Basic criteria: physical, environmental and socio-economic criteria; Sub-criteria are slope, elevation, big soil groups, land use, land use capability classes, distance to road-railways, ports, settlements and electrical energy transmission lines. Consistency rates were calculated for each criterion. The criterion weights calculated in the Analytical Hierarchy Process were overlaid with ArcGIS 10.5 software in the Geographical Information Systems environment and a suitability map for the organic fertilizer plant was obtained. In line with the findings obtained, $81.01 \%$ of Tekirdağ province shows very high-high-medium suitability and existing organic fertilizer facilities are located in these areas. $8.20 \%$ of the province has been found to be very low suitability. The reason for this is that these regions contain national parks and forests. The fact that an organic fertilizer plant is close to the agricultural area is suitable in terms of proximity to the raw material and represents sustainability within the scope of economic input to the country. In this study, AHP method in GIS environment is proposed over Tekirdağ province to be used in the decision-making mechanism of national/international agricultural enterprises. Today, environmental impact assessment reports are generally taken into account in decision-making mechanisms for choosing the appropriate area. However, AHP and similar mathematical models are not used in these reports or decision-makers. In this study, according to the data obtained from the modeling of Tekirdağ province (75.11\% agricultural land, 90\% insufficient organic matter), it is suggested to increase the number of facilities that will meet the organic fertilizer need in the southwest region.
\end{abstract}

Keywords: Geographic Information Systems, Analytic Hierarchy Process, Tekirdağ, Organic Fertilizer Plant, Suitability Analysis 


\section{Giriş}

Tarımsal üretim gıda güvenliği, gıda kalitesi ve ülke ekonomileri bakımından önemli bir konumdadır. Tarımsal ve çevresel sürdürülebilirlik sektörün paydaşları olan çiftçiler, gıda işletmeleri, perakende satış firmaları için önemli bir faktördür. Bu bağlamda işletmelerin kaynaklarını sürdürülebilirlik çerçevesinde kullanımı ham madde temini açısından önemlidir. Hasat sonrası tarımsal alanlarda kalan mahsul kalıntıları, üreticiler tarafindan bir sonraki mahsul için yapılacak hazırlıklara engel olarak görülmektedir. Kalıntıları gidermek için yaygın çözüm yöntemi olarak yakma kullanılmaktadır (Akpınar ve ark., 2009; Gadde ve ark., 2009; Polat, 2015). Son yıllarda dünyadaki tarımsal atık sayısı hızla artmaktadır (Xue ve ark., 2016). Mahsul kalıntılarının yakılması, küresel ısınmayı arttırıcı etkisinin yanı sıra sağlık sorunlarına neden olan ciddi çevresel sorunlara sebebiyet vermektedir (Bhuvaneshwari ve ark., 2019).

Türkiye'de tarım alanlarında çıkan yıllık atık miktarının 50 milyon ton olduğu tahmin edilmektedir (Demirel ve Gürdil, 2018). Organik atıkların toprağa ilavesi sürdürülebilir bir toprak kalitesi için önemlidir. Sürdürülebilir tarım uygulamalarına yönelik farkındalığın artırılması, modern uygulamalarla yapılan organik çiftçiliğin teşvik edilmesi tarım sektörünün çevresel kirliliğe olan etkisinin azalmasında etki sağlayacaktır (Çetin ve ark., 2020). Türkiye topraklarının büyük bir kısmının organik madde bakımından yetersiz olduğu tespit edilmiştir (Güçdemir, 2006; ÇEM, 2018; Sönmez ve ark., 2018). Bellitürk ve Sağlam'ın 2005 y1lında Tekirdağ ili topraklarının mineralize olan azot miktarları ile mineralizasyon kapasiteleri üzerinde yaptıkları araştırmada toprak örnekleri organik madde bakımından $\% 90$ yetersiz bulunurken, fosfor bakımından $\% 45$ zengin bulunmuştur. Organik maddenin toprağa uygulanması toprağın kimyasal verimliliğini arttırmaktadır (Weber ve ark., 2007; Kaur ve ark., 2008; Gómez-Muñoz ve ark., 2017). Bu durumda organik madde kullanımı ürün kalitesi ve sağlığı açısından sektör için gereklidir. Buna bağlı olarak işletmelerin uygun alan seçimi ekonomik, sosyal ve çevresel sürdürülebilirliğin temelini oluşturmaktadır. Tarım işletmelerinin uygun alan seçiminde yapılan çalışmalar sınılıdır ve belirli bir karar mekanizması bulunmamaktadır (Mercan ve ark., 2017).

Yaşanan teknolojik gelişmeler bilginin üretim ve ulaş̧labilirliğini kolaylaştırır iken hızla artan verilerin yönetilmesinde büyük veriyi işlevsel kullanmak için yeni yöntemlere gereksinimi arttırmıştır. Bu bağlamda Coğrafi Bilgi Sistemleri (CBS) verilerin işlenmesinde önemli bir araç olarak ulusal/uluslararası birçok platformda yaygın olarak kullanılmaktadır. CBS verilerin depolanması, görüntülenmesi, düzenlenmesi, sorgulanması ve analizinde istatistiksel ifadelerle değerlendirilme işlemlerinin bütünüdür (Küçükönder ve Karabulut 2007, Ödeker ve Türkoğlu, 2020). CBS ortamında ele alınan Analitik Hiyerarşi Prosesi (AHP) ise karar verme sürecinde en önemli kriterleri belirleyen metod olarak kullanılmaktadır.

Kırsal ekonomileri canlandırmak amacıyla tarımsal işletmelerin uygun alan seçimlerinde bu programların kullanımlarına dair önerileri içeren birçok araştırma bulunmaktadır (Garcia ve ark., 2014; Mishra ve ark., 2015; Herzberg ve ark., 2019; Ünal ve Çetin, 2019; Kumar ve ark., 2021). Bu araştırma içeriklerinde tarımsal sürdürülebilirliğe katkı bağlamında, işletme ihtiyacı olan ürün depo yeri, pazar yeri, tarım arazisi, atık değerlendirilmesine dair tesisler vb. sürece dair yer seçimlerinin yanlış veya hatalı olmasının işletmeleri ekonomik ve sosyal açıdan çok yönlü olarak etkilediği ve ciddi kayıplara neden olduğu vurgulanmaktadır. CBS ile desteklenen AHP yöntemi tarımsal işletmelerin uygun alan seçiminde karar mekanizması oluşturmada etkin olarak kullanılmalı ve tarımsal sürdürülebilirliğe katkı sağlamalıdır.

Bu çalışmada fiziki çevresel ve sosyo-ekonomik koşullar göz önüne alınarak belirlenen kriterler doğrultusunda, CBS ortamında AHP ile örnek bölge seçilen Tekirdağ ili sınırlarında organik gübre tesisi kurulumuna uygun alanların belirlenmesi hedeflenmiştir.

\section{Materyal ve Metot}

Tekirdağ Marmara Bölgesinde, $26^{\circ} 43^{\prime}-28^{\circ} 08^{\prime}$ doğu meridyenleri ile $40^{\circ} 36^{\prime}-41^{\circ} 31^{\prime}$ kuzey paralelleri arasında bulunmaktadır (Şekil l). Yaklaşık $1.200 \mathrm{~km}^{2}$ yüzölçümüne sahiptir. Ortalama yükseltisi yaklaşık $460 \mathrm{~m}$ olan Tekirdağ ili, geniş ovalarıyla dikkat çekmektedir. Yükselti ile eğim kuzeydoğu ve güneybatıya doğru artış göstermektedir. İlin \%75.11'ini oluşturan tarım alanları yükselti ve eğimin az olduğu yerlerde yaygınken; ilin \%15.90'ını kapsayan doğal bitki örtüsü (milli parklar ve ormanlar) yükselti ve eğimin artmaya başladığı yerlerde görülmektedir. 

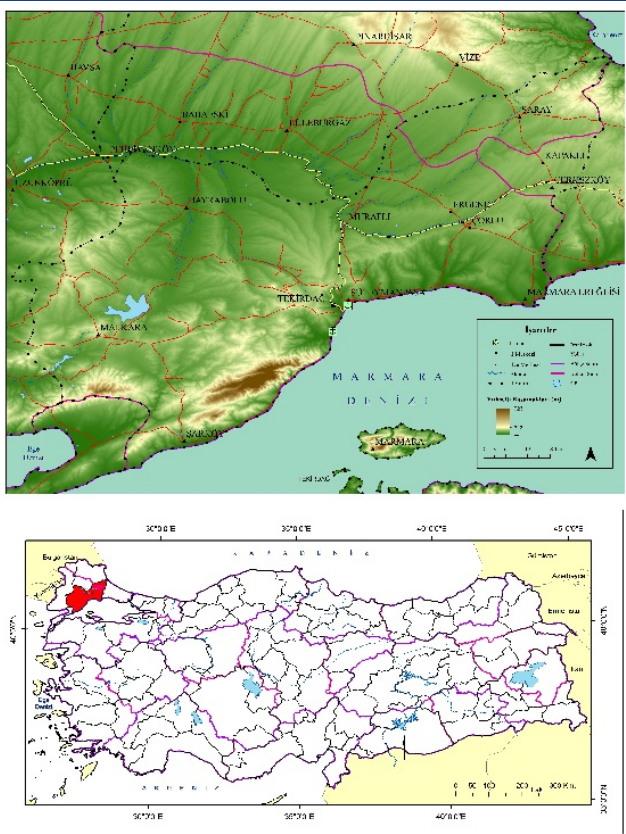

Figure 1. Study area and boundaries

Şekil 1. Çalışma alanı ve sınırları

Çalışmada organik gübre tesislerinin uygunluğunun tespit edilebilmesi için alan yazın taraması sonucu temel ve alt kriterler belirlenmiştir (Şekil 2). Bu kriterlere göre gerekli veriler temin edilerek CBS ortamında ArcGIS 10.5 yazılımı kullanılarak analiz edilmiştir. Bu doğrultuda Tekirdağ ilini kapsayan Corine 2018 arazi örtüsü verileri Avrupa Çevre Ajansı'ndan; 30 metre çözünürlüklü Sayısal Yükseklik Modeli USGS EarthExplorer'dan; 125.000 ölçekli sayısal toprak haritaları Tarım ve Orman Bakanlığı'ndan; su kaynakları, yerleşme ve ulaşım ile ilgili veriler 1250.000 ölçekli topografya haritalarından sağlanmıştır. Tarım ve Orman Bakanlığı 2021 verilerine göre organik gübre tesislerinin konumu Google Earth aracılığıyla belirlenmiş ve CBS ortamında Tabulate Area analizi ile alt kriter grupları içerisindeki organik gübre tesisi sayısı adet olarak belirtilmiştir (Anonim, 2021). Bu sayede kriter gruplarının önem dereceleri ortaya çıkmış ve kriterler buna göre yeniden sınıflandırılmıştır.

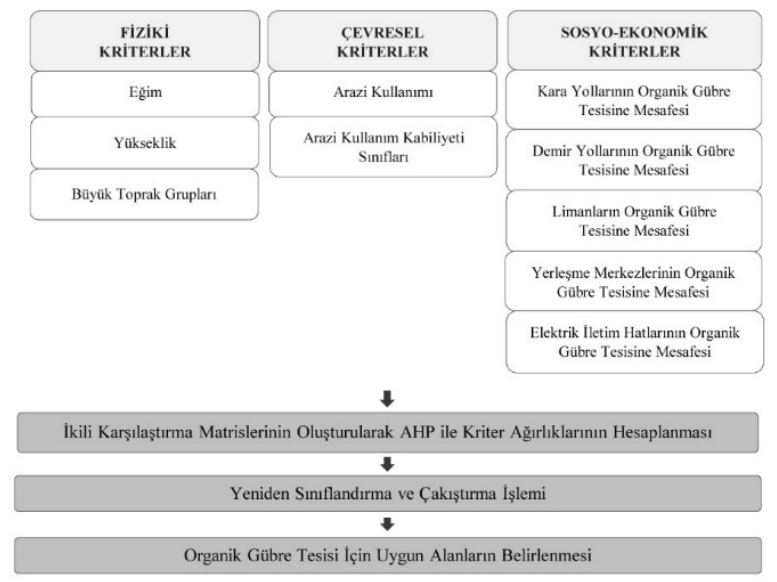

Figure 2. Method scheme

Şekil 2. Yöntem şeması

AHP sürecinde öncelikle temel kriterler (fiziki, çevresel ve sosyo-ekonomik kriterler) için 3x3, alt kriterler (eğim, yükseklik, büyük toprak grupları, arazi kullanımı, arazi kullanım kabiliyeti sınıfları, kara-demir yollarına, limanlara, yerleşim merkezlerine ve elektrik enerjisi iletim hatlarına mesafe) için 10x10 boyutunda ikili karşılaştırma matrisi oluşturulmuştur. Önem dereceleri Saaty'nin 9 seviyeli ölçeğine göre uzman görüşleri doğrultusunda belirlenmiş ve tutarlılık oranı eşitlik 1'e göre değerlendirilmiştir (Saaty, 1980; Saaty, 1990; Saaty ve Alexander, 2015). 
Tutarlılık Oranı $(C R)=\frac{\text { Tutarlılık Göstergesi }\left(C I=\frac{(\lambda \max -n)}{(n-1)}\right)}{\text { Rassallı Göstergesi }(R I)}$

Tutarlılık oranının hesaplanması adına ikili karşılaştırma matrisinin satırları için sütunlardaki kriterler toplam sütun ağırlığına bölünerek normalize matris sağlanmıştır. Bu matrisin her bir satırının ortalaması öncelikler vektörüne, bir başka ifadeyle kriter ağırlıklarına karşılık gelmektedir. Öncelikler vektörünün ikili karşılaştırma matrisi ile çarpılması sonucu elde edilen öncelikler matrisinde her satır toplamı öncelikler vektörüne bölünerek $\lambda$ max değerine ulaşılmıştır. "n" değeri kriter sayısını ifade ederken, rastgele değer indeksi kriter sayısına göre belirlenmektedir. Hesaplamalar doğrultusunda elde edilen değer 0.10 'dan kü̧̈ük olduğu için çalışmanın tutarlı olduğu sonucuna ulaşılmıştır (Saaty, 1977). Mevcut duruma göre yeniden sınıflandırılan kriterler AHP sonucu elde edilen kriter ağırlıkları kullanılarak CBS ortamına aktarılmış ve organik gübre tesisleri için uygunluk analizi gerçekleştirilmiştir.

\section{Araştırma Sonuçları ve Tartışma}

Organik gübre tesislerinin uygunluk analizini gerçekleştirilebilmek için temel ve alt kriterler belirlenmiş, kriterlerin organik gübre tesisleriyle aralarındaki korelasyon, CBS ortamında AHP yöntemi aracillğıyla hesaplanarak, değerlendirilmiştir (Tablo 1).

Tablo 1. Toplam alan içinde mevcut organik gübre tesislerinin sayıst

Table 1. Number of existing organic fertilizer facilities in the total area

\begin{tabular}{|c|c|c|}
\hline Ĕ̆im (\%) & Toplam Alan (\%) & Organik Gübre Tesisi (adet) \\
\hline $0-2$ & 74.08 & 6 \\
\hline $3-4$ & 18.88 & 0 \\
\hline $5-6$ & 4.47 & 0 \\
\hline $7-8$ & 1.48 & 0 \\
\hline $9-10$ & 0.60 & 0 \\
\hline $11-20$ & 0.47 & 0 \\
\hline $21-33$ & 0.00 & 0 \\
\hline $33-50$ & 0.00 & 0 \\
\hline \multicolumn{3}{|l|}{ Yükselti (m) } \\
\hline $4-150$ & 54.70 & 3 \\
\hline $151-300$ & 39.55 & 3 \\
\hline $301-450$ & 3.85 & 0 \\
\hline $451-600$ & 1.12 & 0 \\
\hline $601-750$ & 0.62 & 0 \\
\hline $751-923$ & 0.16 & 0 \\
\hline \multicolumn{3}{|l|}{ Büyük Toprak Grupları } \\
\hline Kireçsiz Kahverengi Orman Toprakları & 1456 & 4 \\
\hline Kahverengi Orman Toprakları & 1010 & 2 \\
\hline Kireçsiz Kahverengi Topraklar & 1889 & 0 \\
\hline Vertisoller & 1236 & 0 \\
\hline Alüvyal Topraklar & 132 & 0 \\
\hline Kestanerengi Topraklar & 1 & 0 \\
\hline Hidromorfik Topraklar & 3 & 0 \\
\hline Diğer & 505 & 0 \\
\hline \multicolumn{3}{|l|}{ Arazi Kullanım Kabiliyeti Sınıfları } \\
\hline $\mathrm{I}$ & 8.62 & 1 \\
\hline II & 43.45 & 3 \\
\hline III & 27.11 & 2 \\
\hline IV & 9.04 & 0 \\
\hline V & 0.04 & 0 \\
\hline VI & 4.65 & 0 \\
\hline VII & 4.95 & 0 \\
\hline VIII & 0.04 & 0 \\
\hline Diğer Alanlar & 2.09 & 0 \\
\hline
\end{tabular}


JOTAF/ Journal of Tekirdag Agricultural Faculty, 2021,18(4)

\begin{tabular}{|c|c|c|}
\hline \multicolumn{3}{|l|}{ Arazi Kullanımı } \\
\hline Yerleşim Alanları & 4.48 & 2 \\
\hline Tarımsal Alanlar & 75.11 & 3 \\
\hline Doğal Bitki Örtüsü & 15.90 & 0 \\
\hline Sulak Alanlar & 0.75 & 0 \\
\hline Otlak Alanları & 3.76 & 1 \\
\hline \multicolumn{3}{|c|}{ Kara Yollarının Organik Gübre Tesisine Mesafesi (km) } \\
\hline $0-2$ & 41.17 & 4 \\
\hline $3-4$ & 24.17 & 2 \\
\hline $5-6$ & 24.17 & 0 \\
\hline $7-8$ & 7.09 & 0 \\
\hline $9-10$ & 2.80 & 0 \\
\hline $11-12$ & 0.59 & 0 \\
\hline $13-14$ & 0.01 & 0 \\
\hline \multicolumn{3}{|c|}{ Demir Yollarının Organik Gübre Tesisine Mesafesi (km) } \\
\hline $0-10$ & 25.68 & 3 \\
\hline $11-20$ & 20.64 & 2 \\
\hline $21-30$ & 15.11 & 1 \\
\hline $31-40$ & 10.81 & 0 \\
\hline $41-50$ & 11.53 & 0 \\
\hline $51-60$ & 8.95 & 0 \\
\hline $61-70$ & 5.75 & 0 \\
\hline $71-80$ & 1.52 & 0 \\
\hline \multicolumn{3}{|c|}{ Limanların Organik Gübre Tesisine Mesafesi (km) } \\
\hline $0-10$ & 4.26 & 1 \\
\hline $11-20$ & 9.81 & 0 \\
\hline $21-30$ & 14.93 & 1 \\
\hline $31-40$ & 17.46 & 0 \\
\hline $41-50$ & 20.56 & 1 \\
\hline $51-60$ & 16.83 & 2 \\
\hline $61-70$ & 10.89 & 0 \\
\hline $70+$ & 5.25 & 1 \\
\hline \multicolumn{3}{|c|}{ Yerleşmelerin Organik Gübre Tesisine Mesafesi (km) } \\
\hline $0-5$ & 12.49 & 3 \\
\hline $6-10$ & 28.61 & 2 \\
\hline $11-15$ & 29.82 & 0 \\
\hline $16-20$ & 19.69 & 1 \\
\hline $21-25$ & 9.19 & 0 \\
\hline $26-30$ & 0.20 & 0 \\
\hline \multicolumn{3}{|c|}{ Elektrik Enerjisi İletim Hattının Organik Gübre Tesisine Mesafesi (km) } \\
\hline $0-2$ & 31.98 & 4 \\
\hline $3-4$ & 21.42 & 1 \\
\hline $5-6$ & 16.29 & 0 \\
\hline $7-8$ & 10.78 & 0 \\
\hline $9-10$ & 7.70 & 0 \\
\hline $11-20$ & 11.13 & 1 \\
\hline $21-30$ & 0.69 & 0 \\
\hline
\end{tabular}

\subsection{Kriterlerin Analizi}

Genellikle düz ve düze yakın bir topografik yapıya sahip olan Tekirdağ ilinin yaklaşık \%74'ü, \%2 eğime sahip olmakla birlikte, ildeki tüm tesisleri kapsamaktadır (Tablo 1, Şekil 3). Yükselti farkı oldukça az olan ilde mevcut organik gübre tesislerinin 300 m’ye kadar konumlanmış olduğu dikkat çekmektedir (Tablo 1, Şekil 4).

Bir organik gübre tesisi kurulurken tesisin tarım alanı yakınında olması ve tarımsal üretimin sağlanabildiği toprak tipinin seçilmesi ham madde temini ve ham maddeye yakınlık açısından önemlidir. Arazi örtüsü sınıfları, arazi kullanım kabiliyeti sınıfları ve toprak özellikleri verileri incelendiğinde Tekirdağ ilindeki tesislerin bu doğrultuda seçim yaptığı görülmektedir (Tablo 1, Şekil 5-6). Arazi kullanım kabiliyeti sınıflarına göre I, II, III, IV sulamaya elverişli tarıma uygun; V, VI, VII sulamaya elverişsiz tarıma uygun; VIII tarıma elverişsiz arazi olarak kodlanmaktadır. Tüm organik gübre tesisleri I, II, III kodlu araziler üzerinde yer almaktadır (Tablo 1, Şekil 7). Bir tesisin ulaşım ve taşıma 
Gürkan \& Ödeker \& Katırcıoglu Coğrafi Bilgi Sistemleri (CBS) Ortamında Analitik Hiyerarşi Prosesiyle (AHP) Organik Gübre Üretim Tesisi Uygunluk Analizi: Tekirdağ İli Örneği açısından kara-demir yolları ile limanlara; pazar imkanı açısından yerleşim merkezlerine ve en önemlisi tesisin faaliyet gösterebilmesi için elektrik enerjisi iletim hatlarına yakın olması gerekmektedir. Tekirdağ ilindeki organik gübre tesisleri kara yollarına $4 \mathrm{~km}$; demir yolarına $30 \mathrm{~km}$; yerleşim merkezlerine ve elektrik enerjisi iletim hatlarına $20 \mathrm{~km}$ yakınlıkta bulunmaktadır (Tablo 1, Şekil 8-9-10-11). Deniz ulaşımı diğer ulaşım türlerine göre daha pahalı olduğu ve uluslararası faaliyet gösterdiği için organik gübre tesislerinin limanlara yakınlık tercihi göreceli bir durum göstermektedir (Tablo 1, Şekil 12).

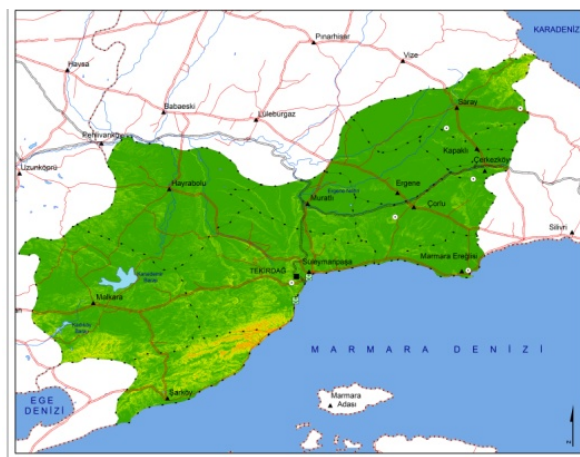

Figure 3. Slope

Şekil 3. Ĕ̈im

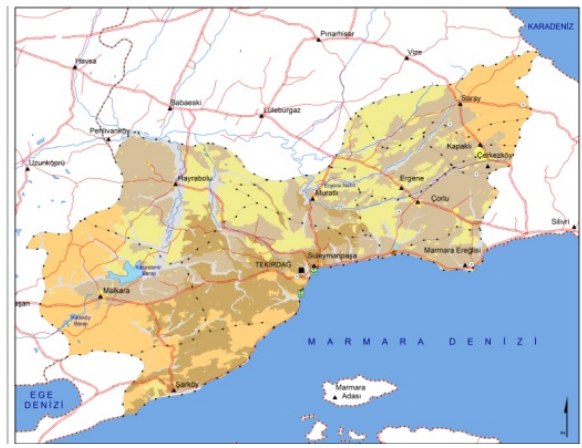

Figure 5. Big Soil Groups

Şekil 5. Büyük toprak gruplart
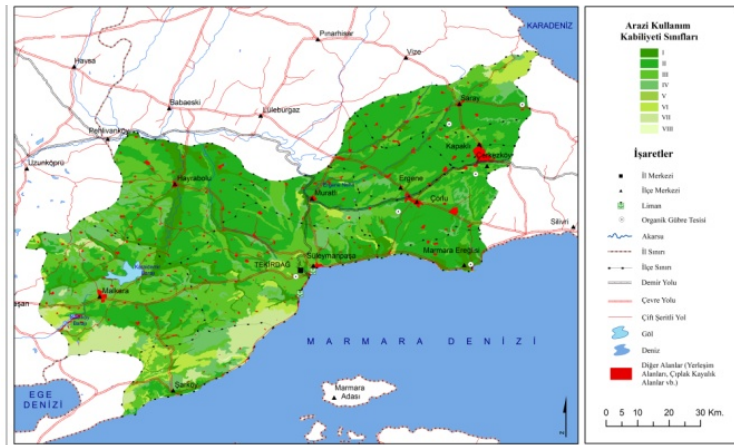

Figure 7. Land use capability classes Şekil 7. Arazi kullanım kabiliyeti sınıfları

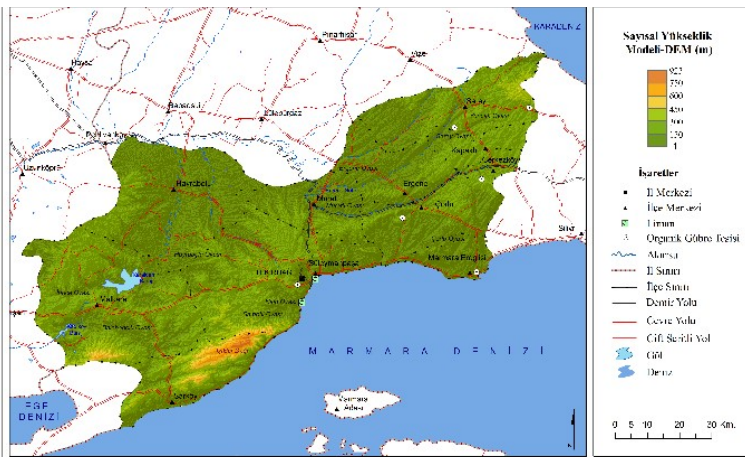

Figure 4. Elevation

Sekil 4. Yükselti
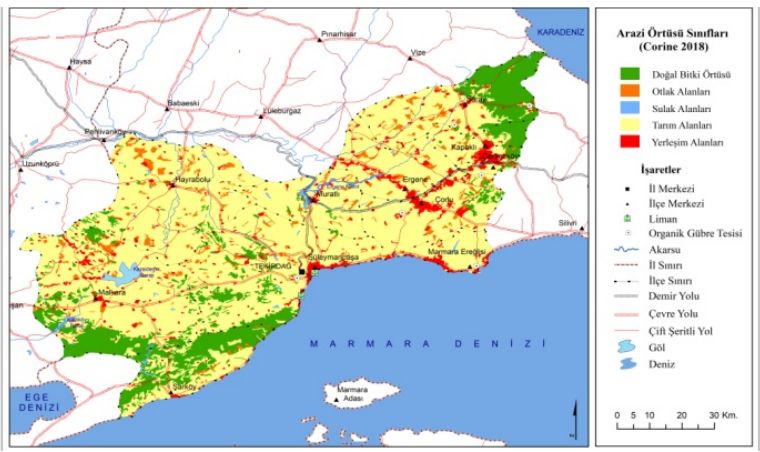

Figure 6. Land use

Şekil 6. Arazi kullanım

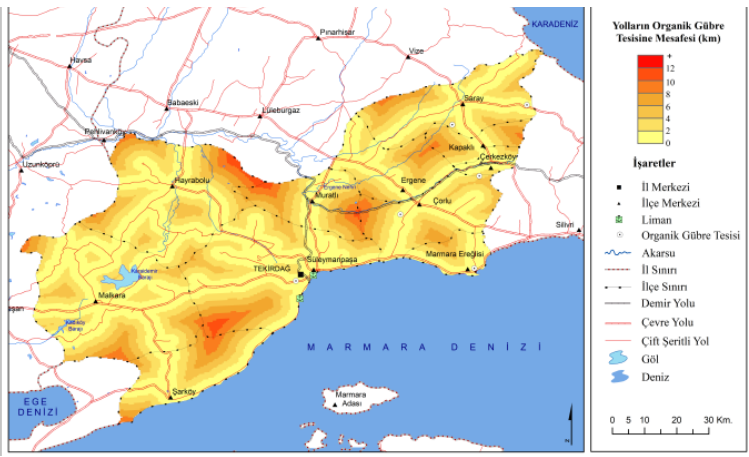

Figure 8. Distance to highways

Şekil 8. Kara yollarına mesafe 
JOTAF/ Journal of Tekirdag Agricultural Faculty, 2021,18(4)

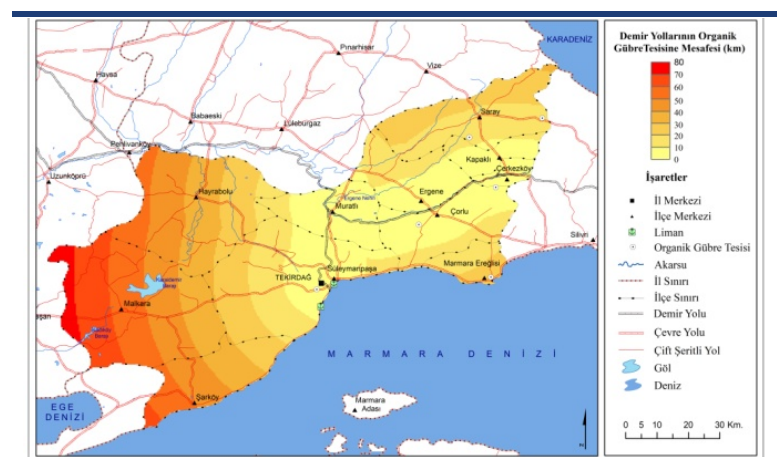

Figure 9. Distance to railways

Şekil 9. Demiryollarına mesafe

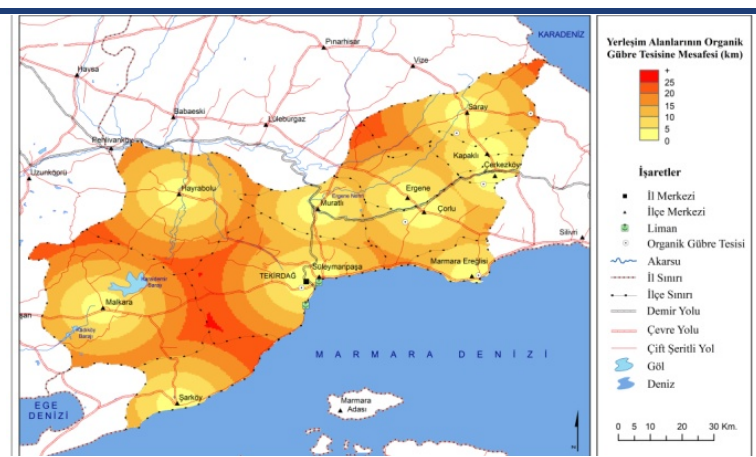

Figure 10. Distance to settlement centers Şekil 10. Yerleşim merkezlerine mesafe

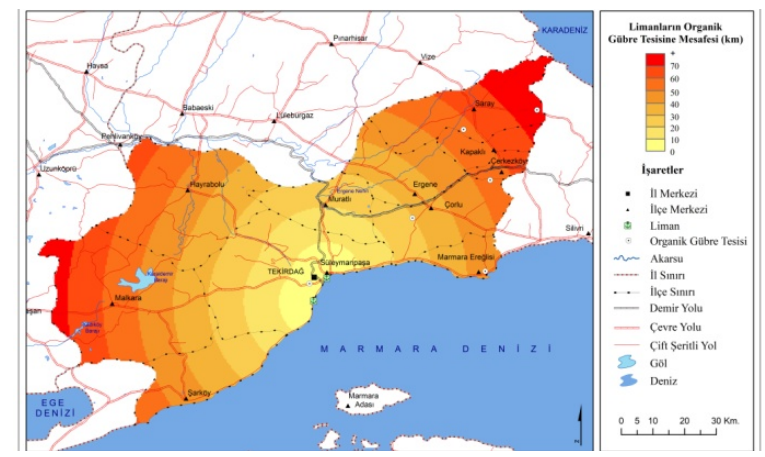

Figure 12. Distance to ports Şekil 12. Limanlara mesafe

Figure 11. Distance to electricity transmission line

Şekil 11. Elektrik iletim hattına mesafe

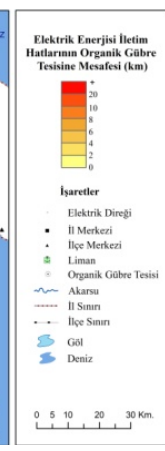

\subsection{AHP ile Kriter A ̈̆ırlıklarının Tayini}

Organik gübre tesislerinin uygunluk analizi doğrultusunda, öncelikle temel kriterlerin ikili karşılaştırma matrisi oluşturularak ağırlıkları belirlenmiş ve tutarlılık oranı hesaplanmıştır (Tablo 2-3).

Tablo 2. Temel kriterler için ikili karşılaştırma matrisi

Table 2. Pairwise comparison matrix for basic criteria

\begin{tabular}{lccc}
\hline & $\begin{array}{c}\text { Fiziki } \\
\text { Kriterler }\end{array}$ & $\begin{array}{c}\text { Çevresel } \\
\text { Kriterler }\end{array}$ & Sosyo-ekonomik Kriterler \\
\hline Fiziki Kriterler & 1 & 0.25 & 0.33 \\
Çevresel Kriterler & 4 & 1 & 1.00 \\
Sosyo-ekonomik Kriterler & 3 & 1 & 1 \\
\hline
\end{tabular}

Tablo 3. Temel kriterler için normalleştirilmiş karşılaştırma matrisi ve öncelikler vektörü (kriter ağırlıkları)

Table 3. Normalized comparison matrix and priority vector (criterion weights) for basic criteria

\begin{tabular}{lcccc}
\hline & $\begin{array}{c}\text { Fiziki } \\
\text { Kriterler }\end{array}$ & $\begin{array}{c}\text { Çevresel } \\
\text { Kriterler }\end{array}$ & $\begin{array}{c}\text { Sosyo-ekonomik } \\
\text { Kriterler }\end{array}$ & $\begin{array}{c}\text { Öncelikler Vektörü } \\
\text { (Kriter } \\
\text { Ağırlıkları) }\end{array}$ \\
\hline Fiziki Kriterler & 0.13 & 0.11 & 0.14 & 0.13 \\
Çevresel Kriterler & 0.50 & 0.44 & 0.43 & 0.46 \\
Sosyo-ekonomik Kriterler & 0.38 & 0.44 & 0.43 & 0.42 \\
\hline
\end{tabular}

İkili karşılaştırma matrisiyle kriter ağırlıkları çarpılarak yeni bir matris oluşturulmuştur. Bu matrisin her satırı toplanarak kriter ağırlıklarına bölünmüştür. Elde edilen değerlerin ortalaması alınarak max değeri 3.0 bulunmuştur. Kriter sayısına göre belirlenen rastgele değer indeksi 0.58 olarak alınmıştır (Saaty, 1987; Eleren, 2010; Altun ve Demir 2015; Misra ve Panda, 2017; Taherdoost, 2017; Oral ve ark., 2021). Tutarlılık oranı hesaplandığında elde edilen sonuç 0.10'dan küçük olduğu için tutarlı olduğu doğrulanmıştır (Eş.2). 
Tutarlılık Oranı $(C R)=\frac{\left(\frac{(3.0-3)}{(3-1)}\right)}{0.58}=0.008$

Aynı yöntem alt kriterlere de uygulanarak kriter ağırlıkları belirlenmiş tutarlılık oranı değerlendirilerek tutarlı olduğu sonucuna ulaşılmıştır (Eş.3, Tablo 4-5). Bu doğrultuda max değeri 10.1 bulunmuştur. Kriter sayısına göre belirlenen rastgele değer indeksi 1.49 olarak alınmıştır (Saaty, 1987; Aguarón ve Moreno-Jiménez, 2003; Alonso ve Lamata, 2006; Eleren, 2010; Altun ve Demir, 2015; Misra ve Panda, 2017; Taherdoost, 2017; Oral ve ark., 2021).

$$
\text { Tutarlılık Oranı }(C R)=\frac{\left(\frac{(10.1-10)}{(10-1)}\right)}{1.49}=0.009
$$

Tekirdağ ilinde mevcut organik gübre tesislerinin bulunduğu kriter aralıkları ve kriter ağırlıkları dikkate alınarak CBS ortamında "Arazi Uygunluk Haritası = (("eğim” * 0.02) + ("yükselti” * 0.03) + ("toprak" *0.06) *0.13) $+($ "arazi kullanımı" * 0.17) + ("arazi kullanım kabiliyeti sınıfları" * 0.12) *0.46) + ("kara yollarına mesafe" * 0.11) + ("demir yollarına mesafe " * 0.07) + ("limanlara mesafe" * 0.06) + ("yerleşim merkezlerine mesafe" * 0.04) + ("elektrik iletim hatlarına mesafe" * 0.31)* 0.42))." formülü ile çakıştırma işlemi yapılmış ve Tekirdağ ilinin organik gübre tesisleri için uygunluk durumu elde edilerek harita üzerinde gösterilmiştir (Şekil 13).

Tablo 4. Alt kriterler için ikili karşılaştırma matrisi

Table 4. Pairwise comparison matrix for sub-criteria

\begin{tabular}{|c|c|c|c|c|c|c|c|c|c|c|}
\hline & 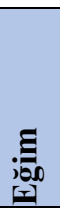 & 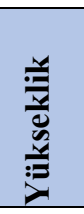 & 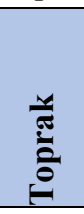 & 昰 & 氧 & 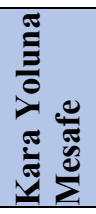 & : & 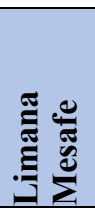 & 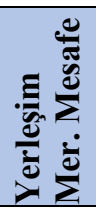 & 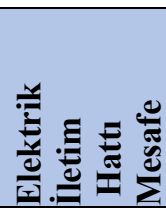 \\
\hline Eğim & 1 & 0.50 & 0.25 & 0.25 & 0.20 & 0.20 & 0.25 & 0.33 & 0.25 & 0.14 \\
\hline Yükseklik & 2 & 1 & 0.33 & 0.33 & 0.25 & 0.25 & 0.33 & 0.50 & 0.33 & 0.17 \\
\hline Toprak & 4 & 3 & 1 & 0.33 & 0.25 & 0.33 & 0.50 & 0.50 & 3 & 0.20 \\
\hline $\begin{array}{l}\text { Arazi Kullanım Kabiliyeti } \\
\text { Sinıfları }\end{array}$ & 4 & 3 & 3 & 1 & 0.50 & 2 & 3 & 4 & 4 & 0.20 \\
\hline Arazi Kullanımı & 5 & 4 & 4 & 2 & 1 & 3 & 4 & 5 & 5 & 0.25 \\
\hline Kara Yollarına Mesafe & 5 & 4 & 3 & 0.50 & 0.33 & 1 & 3 & 3 & 5 & 0.25 \\
\hline Demiryoluna Mesafe & 4 & 3 & 2 & 0.33 & 0.25 & 0.33 & 1 & 2 & 4 & 0.20 \\
\hline Limana Mesafe & 3 & 2 & 2 & 0.25 & 0.20 & 0.33 & 0.50 & 1 & 3 & 0.20 \\
\hline Yerleşim Merkezlerine Mesafe & 4 & 3 & 0.33 & 0.25 & 0.20 & 0.20 & 0.25 & 0.33 & 1 & 0.14 \\
\hline Elektrik İletim Hatlarına Mesafe & 7 & 6 & 5 & 5 & 4 & 4 & 5 & 5 & 7 & 1 \\
\hline
\end{tabular}

Tablo 5. Alt kriterler için normalleştirilmiş karşılaştırma matrisi ve öncelikler vektörü (kriter ağırlıkları) Table 5. Normalized comparison matrix and priority vector (criterion weights) for sub-criteria

\begin{tabular}{|c|c|c|c|c|c|c|c|c|c|c|c|}
\hline & 離 & 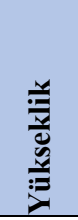 & है & 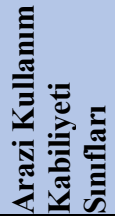 & 可 & 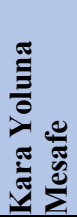 & 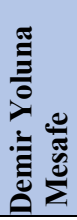 & 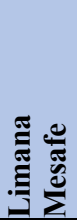 & 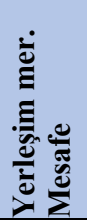 & 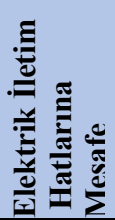 & 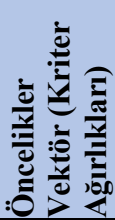 \\
\hline Eğim & 0.03 & 0.02 & 0.01 & 0.02 & 0.03 & 0.02 & 0.01 & 0.02 & 0.01 & 0.05 & 0.02 \\
\hline Yükseklik & 0.05 & 0.03 & 0.02 & 0.03 & 0.03 & 0.02 & 0.02 & 0.02 & 0.01 & 0.06 & 0.03 \\
\hline Toprak & 0.10 & 0.10 & 0.05 & 0.03 & 0.03 & 0.03 & 0.03 & 0.02 & 0.09 & 0.07 & 0.06 \\
\hline $\begin{array}{l}\text { Arazi Kullanım } \\
\text { Kabiliyeti Sınıfları }\end{array}$ & 0.10 & 0.10 & 0.14 & 0.10 & 0.07 & 0.17 & 0.17 & 0.18 & 0.12 & 0.07 & 0.12 \\
\hline Arazi Kullanımı & 0.13 & 0.14 & 0.19 & 0.20 & 0.14 & 0.26 & 0.22 & 0.23 & 0.15 & 0.09 & 0.17 \\
\hline $\begin{array}{l}\text { Kara Yollarina } \\
\text { Mesafe }\end{array}$ & 0.13 & 0.14 & 0.14 & 0.05 & 0.05 & 0.09 & 0.17 & 0.14 & 0.15 & 0.09 & 0.11 \\
\hline Demiryoluna Mesafe & 0.10 & 0.10 & 0.10 & 0.03 & 0.03 & 0.03 & 0.06 & 0.09 & 0.12 & 0.07 & 0.07 \\
\hline Limana Mesafe & 0.08 & 0.07 & 0.10 & 0.02 & 0.03 & 0.03 & 0.03 & 0.05 & 0.09 & 0.07 & 0.06 \\
\hline Yerleşim mer. Mesafe & 0.10 & 0.10 & 0.02 & 0.02 & 0.03 & 0.02 & 0.01 & 0.02 & 0.03 & 0.05 & 0.04 \\
\hline $\begin{array}{l}\text { Elektrik İletim } \\
\text { Hattlarına Mesafe }\end{array}$ & 0.18 & 0.20 & 0.24 & 0.49 & 0.56 & 0.34 & 0.28 & 0.23 & 0.21 & 0.36 & 0.31 \\
\hline
\end{tabular}




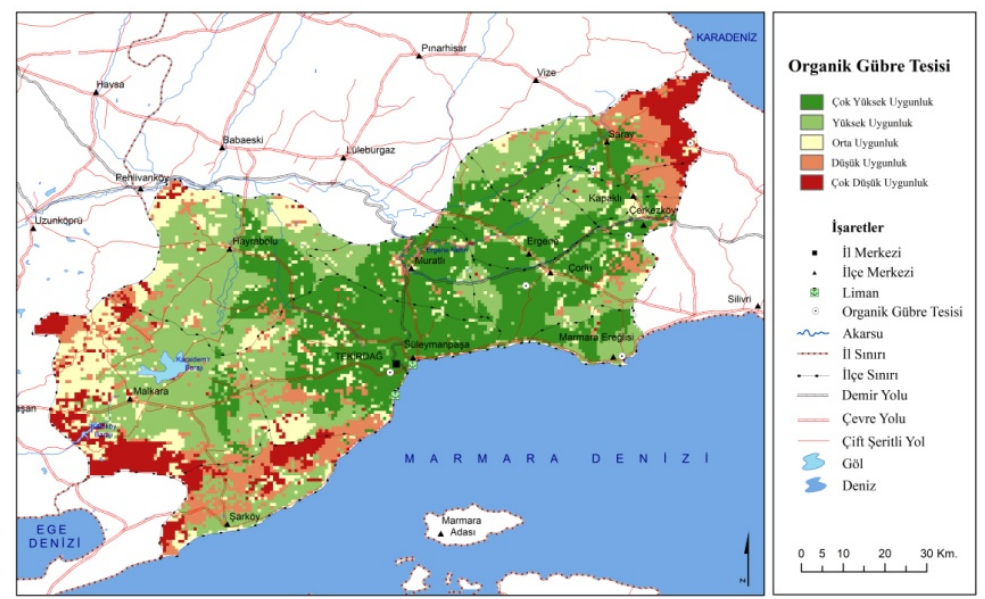

Figure 13. Tekirdağ province organic fertilizer plant suitability map

Şekil 13. Tekirdă̆ ili organik gübre tesisi uygunluk haritası

Tablo 6. Tekirdağ ili uygunluk durumuna göre tesis sayısı

Table 6. Number of facilities according to Tekirdă̆ province eligibility status

\begin{tabular}{lcc}
\hline Uygunluk Durumu & $\begin{array}{c}\text { Toplam Alan } \\
\text { (\%) }\end{array}$ & $\begin{array}{c}\text { Organik Gübre } \\
\text { Tesisi (adet) }\end{array}$ \\
\hline Çok Yüksek & 33.98 & 2 \\
Yüksek & 34.40 & 2 \\
Orta & 12.63 & 2 \\
Düşük & 10.79 & 0 \\
Çok Düşük & 8.20 & 0 \\
\hline
\end{tabular}

Organik gübre tesisi için uygunluk durumu incelendiğinde mevcut tesislerin çok yüksek-yüksek-orta uygunluk gösteren alanlarda yer aldığ görülmektedir. Bu alanlar toplam alanın \%81.01'ini oluşturmaktadır. Toplam alanın \%18.99'u çok düşük ve düşük uygunluk göstermekle beraber bu alanlarda daha çok milli park ve ormanlar bulunmasından dolayı mevcut organik gübre tesisi bulunmamaktadır (Tablo 6).

\section{Sonuç}

Uygun arazi seçim süreci işletmenin sürdürülebilirliği açısından stratejik öneme sahip önemli bir karardır. Bu sürecin doğru yönetilmesi tarımsal işletmelerin ve paydaşlarının, sağlıklı ve uzun süreli bir ticari ekosistem kurmaları konusunda kritik öneme sahiptir. Tekirdağ'daki mevcut organik gübre tesisleri kuzeydoğu bölgesinde, verimin yüksek olduğu tarım alanları üzerinde kurulu olmasından dolayı gübre ihtiyacına yönelik güneybatı bölgesinde de tesislerin sayısının arttırılması önerilmektedir.

CBS ortamında AHP yöntemi doğrultusunda yapılan bu çalışma, bu amaçla yapılacak akademik çalışmaların, tarımsal ve bölgesel kalkınma planlarının yanında hükümetlerin potansiyel tarım politikalarında kararlar almasına olanak sağlayabilecektir. Çalışmanın sonuçları tarımsal üretimde elde dilecek gelirin artmasında, tarımsal yönetim planlarının oluşturulmasında; çiftçilere, bölge planlamacılara ve diğer ilgililerin çıkarım yapmasına uygun niteliktedir. Bir organik gübre tesisinin en uygun koşulların sağlandığı bölgede kurulması özellikle ham madde temininde kolaylık sağlayacağından, üretime faydalı olması ve ekonomik değeri arttırmasıyla sektörün gelişmesini destekleyecektir. Tarımsal atıkların, organik gübre tesislerinde değerlendirilmesi, yakma gibi geleneksel yöntemlerle çevreye verilen zararı azaltıp, küresel ısınmaya etkisini indirgeyerek sürdürülebilir bir çevre doğrultusunda yapılacak iyi tarım uygulamalarına fayda sağlayacaktır. Tarımsal işletmelerin uygun alan seçiminde çevresel sürdürülebilirlik kapsamında, çevre etki raporlarının yanı sıra CBS ortamlarında AHP yöntemi gibi matematiksel modellemelerle elde edilecek verilerin kullanımı ile sosyal ve ekonomik kalkınma planlarını oluşturmada ilgililere önemli bir kılavuz oluşturabilecektir. 


\section{Kaynakça}

Aguarón, J., Moreno-Jiménez, J.M. (2003). The geometric consistency index: Approximated thresholds. European Journal of Operational Research, 147(1), 137-145.

Akpınar, O., Erdoğan, K., Bostancı, S. (2009). Enzymatic production of xylooligosaccharide from selected agricultural wastes. Food and Bioproducts Processing, 87(2), 145-151.

Alonso, J.A., Lamata, M.T. (2006). Consistency in the analytic hierarchy process: a new approach. International Journal of Uncertainty, Fuzziness and Knowledge-based Systems, 14(04), 445-459.

Altun, A., Demir, Y. (2015). Analitik hiyerarşi prosesi yöntemi ile tarımsal araştırma projelerinin değerlendirilmesi ve seçimi. Toprak Su Dergisi, 4(2), 41-48.

Anonim (2021). Tarım Orman Bakanlığg Organik Gübre İşletmeleri, https://www.tarimorman.gov.tr/GKGM/Belgeler/Veteriner\%20Hizmetleri/HayvansalYanUrunIsletme/organik_gubre_tesisleri.pdf, (Erişim Tarihi: 02.02.2021).

Bellitürk, K., Sağlam, M.T. (2005). Tekirdağ ili topraklarının mineralize olan azot miktarları ile mineralizasyon kapasiteleri üzerinde bir araştırma. Tekirdă̆ Ziraat Fakültesi Dergisi, 2(1), 89-101.

Bhuvaneshwari, S., Hettiarachchi, H., Meegoda, J.N. (2019). Crop residue burning in India: Policy challenges and potential solutions. International Journal Of Environmental Research And Public Health, 16(5), 832.

ÇEM. (2018). Toprak Organik Karbonu Projesi, Teknik Özet, Ankara, Türkiye.

Çetin, M , Saygın, S , Demir, H . (2020). Tarım sektörünün çevre kirliliği üzerindeki etkisi: türkiye ekonomisi için bir eşbütünleşme ve nedensellik analizi . Tekirdă̆ Ziraat Fakültesi Dergisi , 17 (3) , 329-345.

Demirel, B., Gürdil, G. (2018). Fındık zurufu atığından yakıt briketi elde edilmesi ve brikete ait bazı özelliklerin belirlenmesi. Anadolu Tarım Bilimleri Dergisi, 33(1), 24-29.

Eleren, A. (2010). Kuruluş yeri seçiminin analitik hiyerarşi süreci yöntemi ile belirlenmesi; deri sektörü örneği. Atatürk Üniversitesi İktisadi ve İdari Bilimler Dergisi, 20(2), 405-416.

Gadde, B., Bonnet, S., Menke, C., Garivait, S. (2009). Air pollutant emissions from rice straw open field burning in India, Thailand and the Philippines. Environmental Pollution, 157(5), 1554-1558.

García, J. L., Alvarado, A., Blanco, J., Jiménez, E., Maldonado, A. A., \& Cortés, G. (2014). Multi-attribute evaluation and selection of sites for agricultural product warehouses based on an analytic hierarchy process. Computers and Electronics in Agriculture, 100, 60-69.

Gómez-Muñoz, B., Magid, J., Jensen, L.S. (2017). Nitrogen turnover, crop use efficiency and soil fertility in a long-term field experiment amended with different qualities of urban and agricultural waste. Agriculture, Ecosystems \& Environment, 240, 300-313Mirik, M. (2005). Biberde bakteriyel leke etmeni Xanthomonas axonopodis pv. vesicatoria'nın tanılanması ve bitki büyüme düzenleyici rizobakteriler ile biyolojik mücadele olanakları. (Doktora Tezi) Çukurova Üniversitesi Fen Bilimleri Enstitüsü, Adana.

Güçdemir, İ.H. (2006). Türkiye Gübre ve Gübreleme Rehberi. S. 1-183. Tarım Orman ve Köyişleri Bakanlığı Toprak Su Genel Müdürlüğü Araştırma Dairesi Başkanlığı Yayın No. 231, Teknik yayın no:T.69, Ankara.

Herzberg, R., Pham, T. G., Kappas, M., Wyss, D., \& Tran, C. T. M. (2019). Multi-criteria decision analysis for the land evaluation of potential agricultural land use types in a hilly area of Central Vietnam. Land, 8(6), 90.

Kaur, T., Brar, B. S., Dhillon, N.S. (2008). Soil organic matter dynamics as affected by long-term use of organic and inorganic fertilizers under maize-wheat cropping system. Nutrient Cycling in Agroecosystems, 81(1), 59-69.

Kumar, A., Pramanik, M., Chaudhary, S., \& Negi, M. S. (2021). Land evaluation for sustainable development of Himalayan agriculture using RS-GIS in conjunction with analytic hierarchy process and frequency ratio. Journal of the Saudi Society of Agricultural Sciences, 20(1), $1-17$.

Küçükönder, M., Karabulut, M. (2007). Çok Kriterli Analiz Yöntemi Kullanılarak Kahramanmaraş’ta Çöp Depolama Alanı Tespiti. Coğrafi Bilimler Dergisi, 5(2), 1-23.

Mercan, Y., Yılmaz, E., Sezgin, F., Ünal, H.B. (2017). Tarımsal işletme yeri seçiminde coğrafi bilgi sistemi destekli çok ölçütlü karar analizi uygulamaları. Gaziosmanpaşa Bilimsel Araştırma Dergisi, 6(Özel Sayı (BSM 2017)), 88-102.

Mishra, A. K., Deep, S., Choudhary, A. (2015). Identification of suitable sites for organic farming using AHP \& GIS. The Egyptian Journal of Remote Sensing and Space Science, 18(2), 181-193.

Misra, S., Panda, R. K. (2017). Environmental consciousness and brand equity: an impact assessment using analytical hierarchy process (ahp). Marketing Intelligence \& Planning.

Oral, N., Yumuşak, R., Eren, T. (2021) AHP ve ANP yöntemleri kullanılarak tehlikeli madde depo yeri seçimi: Kırıkkale ilinde bir uygulama. Niğde Ömer Halisdemir Üniversitesi Mühendislik Bilimleri Dergisi, 10(1), 115-124. 
JOTAF/ Journal of Tekirdag Agricultural Faculty, 2021,18(4)

Ödeker, B., Türkoğlu, N. (2020). Sabuncular Deresi Havzası'nın (Rize/Çayeli) Morfometrik Özelliklerinin Coğrafi Bilgi Sistemleri (CBS) İle Belirlenmesi. Ankara Üniversitesi Dil ve Tarih-Coğrafya Fakültesi Dergisi, 60(1), 14-38.

Polat, M. (2015). Bir organik gübre tesisine ait üretim hattı üniteleri. Tarım Makinaları Bilimi Dergisi, 11(3), 275-283.

Saaty, R.W. (1987) The analytic hierarchy process - what it is and how it is used. Mathematical Modelling, 9(3-5), 161-176.

Saaty, T. L. (1977). A Scaling Method For Priorities In Hierarchical Structures. Journal of Mathematical Psychology, 15(3), $234-281$.

Saaty, T. L. (1980) The Analytical Hiyerarchy Process. New York: Mc Grow-Hill Company.

Saaty, T.L. (1990). How to make a decision: the analytic hierarchy process. European Journal of Operational Research, 48(1), 9-26.

Saaty, T.L., Alexander, J.M. (2015). Thinking with models. Pittsburg: RWS Publications.

Sönmez, B., Özbahçe, A., Akgül, S., Keçeci, M. (2018). Türkiye Topraklarının Bazı Verımlilik Ve Organik Karbon (TOK) İçeriğinin Coğrafi Veritabanının Oluşturulması (in Turkish). Tarım ve Orman Bakanlı̆̆ı, Tarımsal Araştırmalar ve Politikalar Genel Müdürlüğü Proje Sonuç Raporu TAGEM. Tarım ve Orman Bakanlığı, Tarımsal Araştırmalar ve Politikalar Genel Müdürlüğ̈̈ Proje Sonuç Raporu TAGEM, 13.

Taherdoost, H. (2017). Decision Making Using the Analytic Hierarchy Process (AHP); A Step By Step Approach. International Journal of Economics and Management Systems, 2, 244-246.

Ünal, Z., Çetin, E.İ. (2019). Gübre üreticisinin hedef pazar seçiminde bütünleşik AHP-TOPSIS yöntemi. Mediterranean Agricultural Sciences, 32(3), 357-364.

Weber, J., Karczewska, A., Drozd, J., Licznar, M., Licznar, S., Jamroz, E., Kocowicz, A. (2007). Agricultural and ecological aspects of a sandy soil as affected by the application of municipal solid waste composts. Soil Biology and Biochemistry, 39(6), 1294-1302.

Xue, L., Zhang, P., Shu, H., Wang, R., Zhang, S. (2016). Agricultural waste. Water Environment Research, 88(10), 1334-1369. 